\title{
The Characteristic Analysis of Caffeine Molecularly Imprinted Polymers Synthesized Using The Cooling-Heating Method, for Application as a Sensor Material
}

\author{
Idha Royani' ${ }^{1 *}$, Amalia $^{1}$, Jorena ${ }^{1}$, Fitri Suryani Arsyad ${ }^{1}$, Erry Koriyanti ${ }^{1}$, Fiber Monado ${ }^{1}$ \\ ${ }^{1}$ Department of Physics, Faculty of Mathematics and Natural Sciences, Sriwijaya University, Palembang, 30662, Indonesia \\ *Corresponding author: idharoyani@unsri.ac.id
}

\begin{abstract}
The cooling-heating method was used to successfully synthesize molecularly imprinted polymers on caffeine. Caffeine was used as a template and mixed with chloroform solvent, methacrylic acid as a monomer, ethylene glycol dimethacrylate as a cross-linker, and benzoyl peroxide as an initiator. The solution was stirred for 15 minutes and placed in a vial. Then it was placed in a cooler with a temperature of $-5^{\circ} \mathrm{C}$ for 60 minutes and then inserted into an oven with an increasing temperature at $75^{\circ} \mathrm{C}, 80^{\circ} \mathrm{C}$, and $85^{\circ} \mathrm{C}$ for 3,2 and 1 hour, respectively. Furthermore, the repeated washing process resulted in solid polymer, which was subjected to template leaching to produce polymers with specific cavities called molecularly imprinted polymers (MIP). The resulting caffeine polymer and MIP were tested using SEM, FTIR, and XRD methods. In addition, the SEM image analysis data showed 388 cavities in the polymer after template leaching, compared to the 121 cavities in the unwashed polymer. This result was supported by the FTIR spectrum analysis which showed that caffeine MIP has a higher transmittance value than the polymer. Therefore, the caffeine concentration was significantly reduced after the leaching process. The XRD spectra showed that caffeine MIP had a smaller half-maximum diffraction peak width (FWHM) compared to the polymer. Also, the low FWHM value depicted a larger crystalline size in the caffeine MIP compared to the polymer.
\end{abstract}

Keywords

Caffeine, Cavities, Cooling-Heating, MIP, Polymerization

Received: 5 May 2021, Accepted: 23 August 2021

https://doi.org/10.26554/sti.2021.6.4.256-260

\section{INTRODUCTION}

Caffeine is found in foods and beverages, including coffee, tea, cola, and chocolate, though excessive consumption may harm the body (Wolde, 2014). Coffee is an example of a beverage with high levels of caffeine (antioxidants), and it is four times that of tea (Escott-Stump, 2008). In addition, caffeine acts as a central nervous system stimulant with a similar effect to amphetamine, though weaker (McCormack and Hoffman, 2012).

The molecular imprinting technique was used to analyze caffeine content simply and cheaply, while maintaining high selectivity. Generally, it is a technique used to produce polymers with cavities from specific molecules, with behavior that mimic the receptors binding in particular locations. This enables the recognition of molecules with the similar size, structure, and physicochemical properties (Liang et al., 2009). Furthermore, the polymer cavities are formed using the template leaching process, which occcurs after the polymerization process is completed (Komiyama et al., 2003). Also, this polymer material was used as a sensor to identify chemical and biological elements
(Mustaghfiroh et al., 2019; Ahmad et al., 2019; Mirmohseni et al., 2014; Mazzotta et al., 2008). The selectivity and affinity of the template increase as concentration values increase (Lavignac et al., 2006).

Several studies have been conducted to synthesize caffeine molecular imprinted polymer (MIP) (Shou-Lian et al., 2012; Tian et al., 2017), though the synthesis reactions require a long time. For example, previous caffeine MIP polymerization processes takes 16 hours (Farrington et al., 2006), 24 hours (Hidayat and Sunarto, 2017), and 48 hours (Cormack and Mehamod, 2013) to complete using nitrogen flow and immersing the polymer into a water bath. However, this duration can be overcome using the cooling-heating method in the polymerization process, which was tested in several active substances without reducing the characteristics of the resulting polymer (Royani and Abdullah, 2014; Nurhayati et al., 2016; Koriyanti et al., 2020).

The synthesis of caffeine MIP was successfully conducted in this study. In addition, the polymers produced were confirmed to have cavities that match the analyte, when the appropriate 
solvent and template leaching process was applied. The results showed that the the cooling-heating method was used to synthesize caffeine polymer successfully in a relatively short time ( 7 hours), resulting in caffeine MIP with more cavities than the unwashed polymer. Furthermore, the heating process is carried out after the cooling process by increasing the temperature. This treatment accelerate the binding process of caffeine particles and monomer function, allowing the solid polymer to form faster. Therefore, this indicated that the template leaching process was successful, and the resulting MIP has the potential to be used as a sensor material.

\section{EXPERIMENTAL SECTION}

\subsection{Materials}

This study used the following ingredients: caffeine (p.a Sigma Aldrich), methacrylic acid (MAA, p.a Merck), ethylene glycol dimethacrylate (EDMA, p.a Merck), benzoyl peroxide (BPO, p.a Merck), chloroform (p.a Merck), acetonitrile (p.a Merck), methanol (p.a Merck), acetic acid (p.a Merck), and aquabidest (p.a Merck).

\subsection{Methods}

\subsubsection{Caffeine MIP Synthesis}

A sample of $0.025 \mathrm{~g}$ caffeine $\left(\mathrm{C}_{8} \mathrm{H}_{10} \mathrm{~N}_{4} \mathrm{O}_{2} ; 1.2 \mathrm{~g} / \mathrm{cm}^{3}\right.$ density) was mixed in a tube containing $2.01 \mathrm{~mL}$ of chloroform $\left(\mathrm{CHCl}_{3} ; 1.49 \mathrm{~g} / \mathrm{cm}^{3}\right.$ density). Then, the solvent was treated using $0.3 \mathrm{~mL}$ MAA $\left(\mathrm{C}_{4} \mathrm{H}_{6} \mathrm{O}_{2} ; 1.015 \mathrm{~g} / \mathrm{cm}^{3}\right.$ density $)$ as a functional monomer, $0.525 \mathrm{~mL}$ EDMA $\left(\mathrm{C}_{10} \mathrm{H}_{14} \mathrm{O}_{4} ; 1.05 \mathrm{~g} / \mathrm{cm}^{3}\right.$ density) as cross-linker, and $0.07 \mathrm{~g}$ BPO $\left(\mathrm{C}_{14} \mathrm{H}_{10} \mathrm{O}_{4} ; 1.33\right.$ $\mathrm{g} / \mathrm{cm}^{3}$ density) as initiator. A magnetic stirrer was used in the reagents for 15 minutes and the solution was placed into a vial and closed tightly. The cooling process was carried out by inserting the vial into the cooler at a temperature of $-5^{\circ} \mathrm{C}$ for 60 minutes and heating in a furnace at a temperature of $75^{\circ} \mathrm{C}$ for 3 hours, $80^{\circ} \mathrm{C}$ for 2 hours, and $85^{\circ} \mathrm{C}$ for 1 hour consecutively. A solid polymer is obtained after the heating process is complete, which is ground to a fine polymer powder.

\subsubsection{Template Leaching}

The resulting polymer particles were washed using acetonitrile to remove caffeine and obtain caffeine MIP, which recognizes a target with similar characteristics as itself.

\subsubsection{Characteristic Test}

Furthermore, the resulting polymers were characterized using the Hitachi Flexsem 1000 Scanning Electron Microscopy (SEM), 8201PC Shimadzu Fourier Transform Infrared Spectrophotometer (FTIR), and PW3710 X-Ray Diffraction (XRD) to study its cavities, identify the functional groups and determine the crystal size, respectively.

\section{RESULTS AND DISCUSSION}

The cooling-heating method used for the polymer synthesis process showed the expected results. Furthermore, the solid polymer synthesis process was completed in a short time, taking 7 hours less than previous studies of caffeine MIP synthesis, which takes a long time using the nitrogen flow method (Farrington et al., 2006; Hidayat and Sunarto, 2017; Cormack and Mehamod, 2013).

\subsection{Scanning Electron Microscope (SEM) Characterization Test on Caffeine Polymers and MIP}

The SEM characterization test aimed to determine the surface morphology and the number of cavities formed by the extraction process in the sample. Therefore, this study compared the SEM characterization of unwashed polymer samples and caffeine MIP. Figure 1 showed the results of the SEM test.
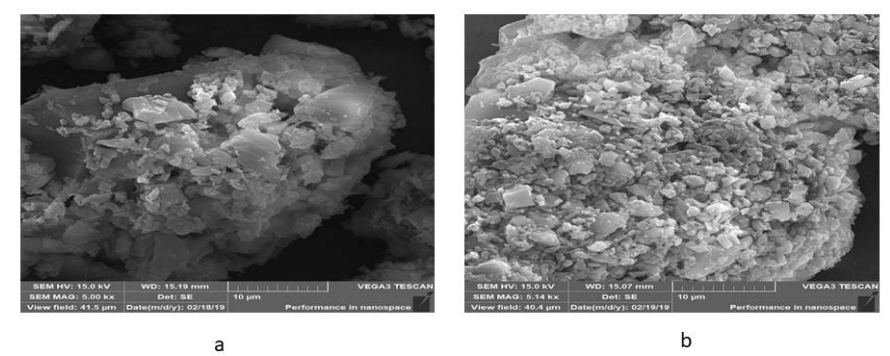

Figure 1. SEM Images of (a) Caffeine Polymer and (b) Caffeine MIP

Figure 1 was fed to the Poredisc software, which counted the number and size of cavities from each sample as described in Figure 2. The results showed that the number and size of the cavities differ significantly between the caffeine polymer and MIP. Figure la indicated that caffeine was bound to MAA as a monomer, while Figure $1 \mathrm{~b}$ showed caffeine release from the polymer due to the leaching process conducted.

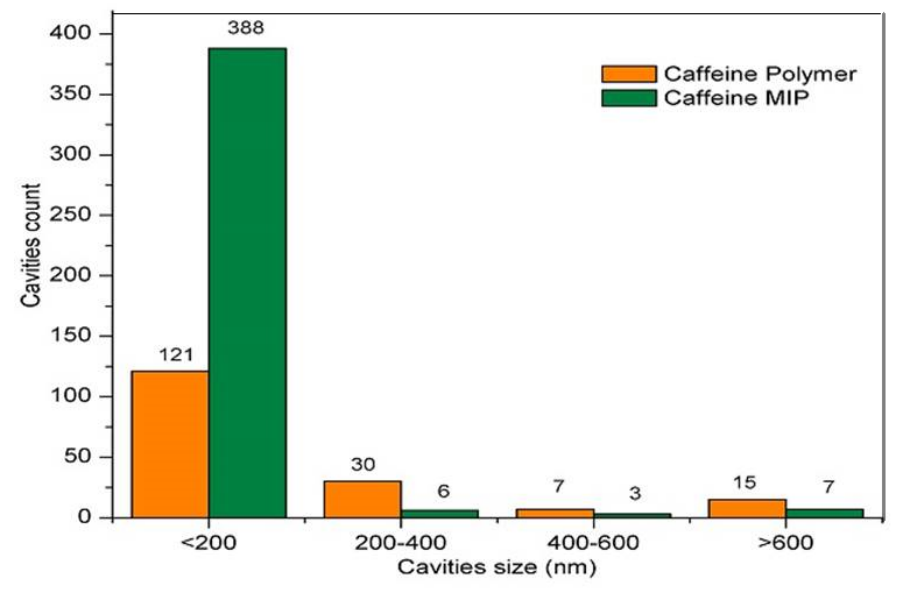

Figure 2. Comparison of The Number of Cavities in Unwashed Polymer and Caffeine MIP

Figure 2 showed that the unwashed polymer sample has fewer cavities than the caffeine MIP. According to the $<200$ 
nm category, the unwashed polymer and caffeine MIP has 121 and 388 cavities, respectively. This result showed that the solvent used in the leaching process dissolves caffeine and forms numerous cavities. Therefore, these cavities will be recognized again if a target has the same physical and chemical properties (Komiyama et al., 2003). This principle is the basis of the MIP material's sensor function. However, to obtain fewer cavities than MIP caffeine no leaching process is conducted in the caffeine polymer. According to this SEM characterization, the caffeine MIP produced can be used as a sensor material with high selectivity and sensitivity (Royani and Abdullah, 2014).

\subsection{Fourier Transform Infrared (FTIR) Characterization- Test}

FTIR was used to determine the functional groups of a compound in a sample. The FTIR test generated a transmittance value graph associated with the absorbance and concentration values of the tested sample. Figure 3 showed the graph from the FTIR analysis of the model

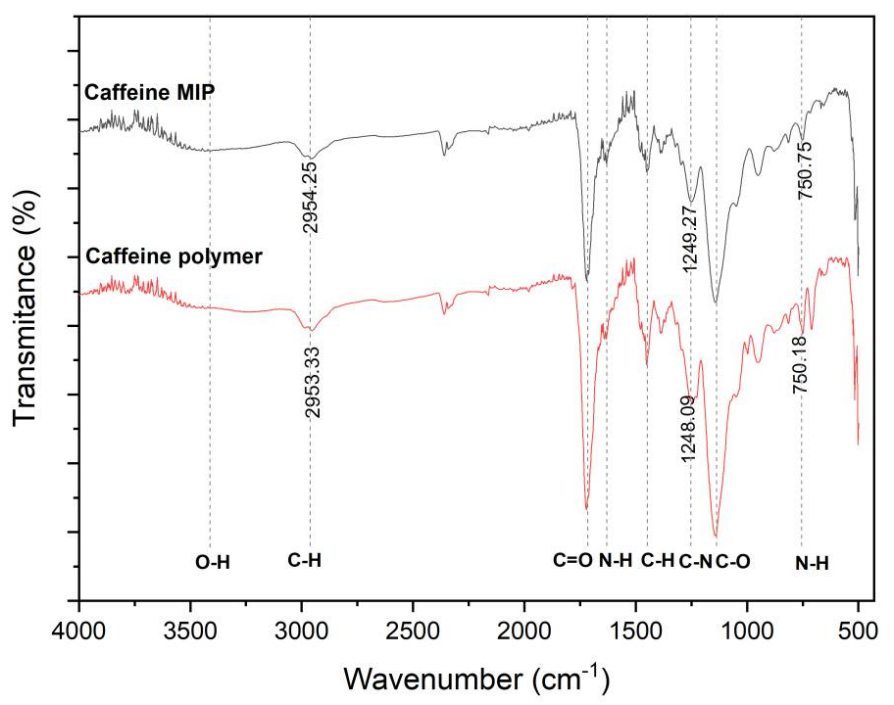

Figure 3. FTIR Spectrum of Caffeine MIP and Caffeine Polymer

In addition, the polymer's FTIR spectrum before and after the template leaching process has the following peaks. The weak peaks at wavenumber $750.18 \mathrm{~cm}^{-1}$ and $750.75 \mathrm{~cm}^{-1}$ are $\mathrm{N}-\mathrm{H}$ wagging vibrations of secondary amine groups for the polymer before and after template leaching, respectively. The increase in the polymer transmittance value after template leaching (MIP), from $92 \%$ to $97 \%$, indicated a decrease in caffeine concentration after extraction. Furthermore, caffeine measurements showed a strong $\mathrm{C}-\mathrm{H}$ stretching vibration on methyl $\left(-\mathrm{CH}_{3}\right)$ and $\mathrm{C}-\mathrm{H}$ bending vibration at wavenumber 2953.33-2954.25 $\mathrm{cm}^{-1}$ and 1384.45-1390.02 $\mathrm{cm}^{-1}$, respectively (Silverstein and Bassler, 1962). The higher transmittance values in MIP, which are $95 \%$ and $96 \%$, respectively, compared to the polymer, $92 \%$, indicated that some caffeine was washed off due to leaching.

Furthermore, the peaks at $1632.02 \mathrm{~cm}^{-1}$ and 1650.09 $\mathrm{cm}^{-1}$ showed an overlap between the $\mathrm{C}=\mathrm{C}$ stretching vibrations and the N-H bending of the atoms in the caffeine molecule. Therefore, the higher transmittance value of caffeine MIP indicated that the amount of caffeine in the polymer decreased after the leaching process. However, the peaks at wavenumber $1721.13 \mathrm{~cm}^{-1}$ and $1720.82 \mathrm{~cm}^{-1}$ indicated the $\mathrm{C}=\mathrm{O}$ stretching vibration of MAA and EDMA as the functional monomer and cross-linker, respectively.

According to the FTIR spectrum, the caffeine MIP sample (after the template leaching process) has a lower concentration than the polymer, indicated by the higher transmittance value of caffeine MIP compared to the polymer. Therefore, the greater the transmittance value, the smaller the absorbance, indicating that the concentration is diminutive. The leaching process carried out on the polymer aimed to release the caffeine bond, hence creating cavities. Consequently, the caffeine MIP has a lower concentration compared to the polymer.

The presence of an alcohol functional group at wavenumber $3434.41 \mathrm{~cm}^{-1}$ in caffeine MIP is due to the addition of methanol solution in the extraction process, which is part of the functional group (Skoog et al., 2017).

\subsection{X-Ray Diffraction (XRD) Characterization Test Analy- sis}

XRD characterization aimed to determine the sample crystal size. The size was obtained in Equation 1, which is known as the Debye Scherrer Equation.

$$
L=\frac{K \lambda}{\mathrm{B} \cos \theta}
$$

The graph in Figure 4 showed the results from the XRD analysis of the sample.

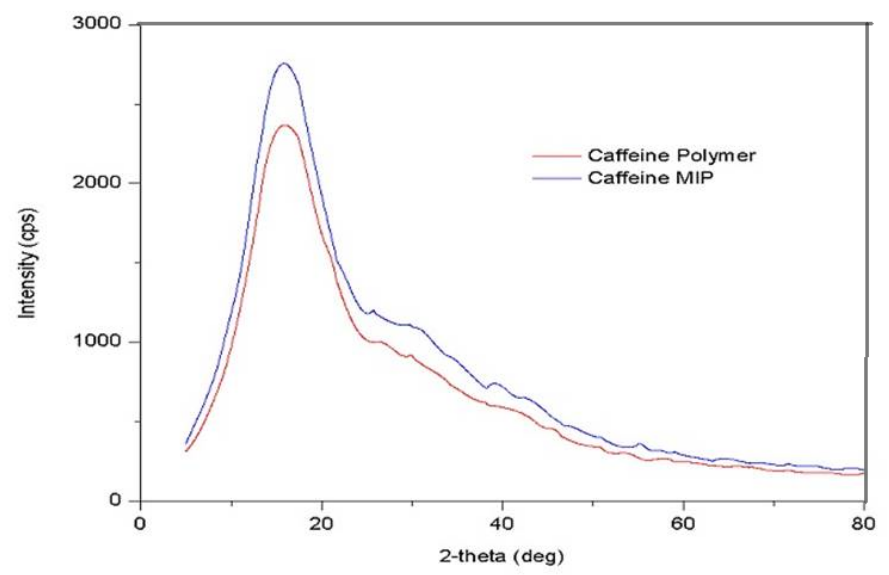

Figure 4. XRD Caffeine Polymer and Caffeine MIP XRD Graph 
Table 1. Analysis of The XRD Pattern of The Caffeine Polymer and The Caffeine MIP

\begin{tabular}{ccccc}
\hline Sample & $\begin{array}{c}2 \text {-Theta } \\
\left({ }^{\circ}\right)\end{array}$ & $\begin{array}{c}\text { D-Spacing } \\
(\AA)\end{array}$ & $\begin{array}{c}\text { FWHM } \\
\left({ }^{\circ}\right)\end{array}$ & $\begin{array}{c}\text { Crystal Size } \\
(\AA)\end{array}$ \\
\hline Caffeine Polymer & 16.01 & 5.53 & 8.5 & 0.94 \\
Caffeine MIP & 15.77 & 5.61 & 7.88 & 0.97 \\
\hline
\end{tabular}

Figure 4 indicated the difference in intensity values between caffeine polymer and caffeine MIP. The relatively higher intensity peak in the caffeine MIP compared to the polymer indicated that more atoms were diffracted in the MIP. Also, a larger crystal size provided a significant number of atoms in the crystal plane. The sample's relatively large peak widths showed that the crystallinity size of caffeine polymer and MIP is small (Abdullah et al., 2009).

The values presented in Table 1 help read the XRD pattern from the comparison. Table 1 showed that the caffeine MIP has a larger crystal size than the caffeine polymer from the two XRD samples, resulting in its smaller FWHM value (see Equation 1). This value indicated a larger crystalline size in the caffeine MIP compared to the polymer. Also, the immersion process during extraction can increase the crystallite size of the caffeine MIP. This increase in size is accompanied by increased cavities, which are places left by caffeine in the polymer. Therefore, the concentration of caffeine in MIP becomes smaller than that of the polymer. The caffeine MIP cavity is a characteristic required in sensor applications to obtain high sensitivity and selectivity values (Royani and Abdullah, 2014).

\section{CONCLUSIONS}

The caffeine polymer particles synthesized using the coolingheating method were subjected to the template leaching process. Consequently, the results showed a decrease in caffeine concentration. Measurements using the SEM software showed that the polymer subjected to the template leaching process had 388 cavities compared to 121 cavities in the unwashed polymer. The FTIR spectrum depicted a higher percent transmittance for the $\mathrm{C}-\mathrm{H}$ stretching vibration on methyl $\left(-\mathrm{CH}_{3}\right)$ and caffeine for the MIP (wavenumber $1390.02 \mathrm{~cm}^{-1}$ and $2954.25 \mathrm{~cm}^{-1}$ ) than the unwashed polymer. Therefore, this indicated that the template leaching process was successfully completed. The results of the XRD characterization showed that the crystal size for caffeine MIP was larger than that of the unwashed polymer, corresponding to the observed FWHM value. The characteristics of the caffeine MIP indicated that it has the potential to be used as a sensor material.

\section{ACKNOWLEDGEMENT}

The author is grateful to the leadership of the Sriwijaya University for the moral and material support through the competitive grant research. SP DIPA-023.17.2.677515/2021, On November 23, 2020. In accordance with the Rector's Decree Number: 0010/UN9/SK.LP2M.PT/2021, ON April 28, 2021.

\section{REFERENCES}

Abdullah, M., K. Khairurrijal, and K. Khairurrijal (2009). Karakterisasi nanomaterial. Jurnal Nanosains \& Nanoteknologi, 2(1); 1-9

Ahmad, O. S., T. S. Bedwell, C. Esen, A. Garcia-Cruz, and S. A. Piletsky (2019). Molecularly imprinted polymers in electrochemical and optical sensors. Trends in Biotechnology, 37(3); 294-309

Cormack, P. A. and F. S. Mehamod (2013). Molecularly imprinted polymer synthesis using RAFT polymerisation. Sains Malays, 42; 529-535

Escott-Stump, S. (2008). Nutrition and Diagnosis-Related Care. Lippincott Williams \& Wilkins

Farrington, K., E. Magner, and F. Regan (2006). Predicting the performance of molecularly imprinted polymers: Selective extraction of caffeine by molecularly imprinted solid phase extraction. Analytica Chimica Acta, 566(1); 60-68

Hidayat, A. R. and S. Sunarto (2017). Aplikasi MIP (Molecularly Imprinted Polymer) dengan Metanol sebagai Ekstraktan Template dalam Sintesisnya untuk Penentuan Kadar Kafein. Jurnal Kimia Dasar, 6(2); 45-52

Komiyama, M., T. Takeuchi, T. Mukawa, and H. Asanuma (2003). Molecular Imprinting: from Fundamentals to Applications

Koriyanti, E., K. Saleh, F. Monado, F. Syawali, and I. Royani (2020). On the effect of ethanol solution on melamine template removal process. Journal of Chemical Technology and Metallurgy, 1(55); 34-49

Lavignac, N., K. R. Brain, and C. J. Allender (2006). Concentration dependent atrazine-atrazine complex formation promotes selectivity in atrazine imprinted polymers. Biosensors and Bioelectronics, 22(1); 138-144

Liang, R., R. Zhang, and W. Qin (2009). Potentiometric sensor based on molecularly imprinted polymer for determination of melamine in milk. Sensors and Actuators B: Chemical, 141(2); 544-550

Mazzotta, E., R. Picca, C. Malitesta, S. Piletsky, and E. Piletska (2008). Development of a sensor prepared by entrapment of MIP particles in electrosynthesised polymer films for electrochemical detection of ephedrine. Biosensors and Bioelectronics, 23(7); 1152-1156

McCormack, W. P. and J. R. Hoffman (2012). Caffeine, energy drinks, and strength-power performance. Strength $\mathcal{E}^{\circ}$ Conditioning Journal, 34(4); 11-16

Mirmohseni, A., R. Pourata, and M. Shojaei (2014). Application of molecularly imprinted polymer for determination of glucose by quartz crystal nanobalance technique. IEEE 
Sensors Journal, 14(8); 2807-2812

Mustaghfiroh, A. M., A. Mulyasuryani, and U. Andayani (2019). Development of chlorpyrifos sensor using molecularly imprinted polymer (mip) polyvinyl alcohol (PVA)$\mathrm{Fe}_{3} \mathrm{O}_{4}$ as receptor. Journal Pure Application Chemistry Research, 8; 31-39

Nurhayati, T., I. Royani, et al. (2016). Synthesis and study of guest-rebinding of MIP based on MAA prepared using theophylline template. Journal of Physics: Conference Series, 739(1); 012127

Royani, I. and M. Abdullah (2014). An atrazine molecularly imprinted polymer synthesized using a cooling-heating method with repeated washing: Its physico-chemical characteristics and enhanced cavities. International Journal of Electrochemical Science, 9; $5651-5662$

Shou-Lian, W., G. Xiao-Jun, W. Hong-Wu, T. Yong-Xin, and
Y. Zi-Jun (2012). Preparation of caffeine molecularly imprinted polymers and application on solid phase extraction. Chinese Journal of Analytical Chemistry, 40(7); 1071-1075

Silverstein, R. M. and G. C. Bassler (1962). Spectrometric identification of organic compounds. Journal of Chemical Education, 39(11); 546

Skoog, D. A., F. J. Holler, and S. R. Crouch (2017). Principles of Instrumental Analysis. Cengage learning

Tian, D.-T., Y.-C. Zhou, L. Xiong, and F.-T. Lu (2017). Synthesis and properties of caffeine molecularly imprinted polymers based on konjac glucomannan. Advances in Polymer Technology, 36(1); 68-76

Wolde, T. (2014). Effects of caffeine on health and nutrition: A Review. Food Science and Quality Management, 30; 59-65 